\title{
Avaliação da Expressão do Antígeno 503 de Leishmania I. Chagasi por Escherichia coli M15 Utilizando Diferentes Concentrações de IPTG
}

\author{
Estéfani A. Asevedo, Vitor T. I. Ribeiro \& Everaldo S. dos Santos
}

\begin{abstract}
A leishmaniose visceral é uma doença parasitária infecciosa causada por protozoários do gênero Leishmania, que pode ser letal quando não é feito um tratamento adequado. $\mathrm{O}$ aumento da incidência desta doença torna importante a busca por alternativas de baixo custo para diagnóstico rápido e vacinas. Nesse contexto, o principal objetivo desta pesquisa foi avaliar a influência do IPTG na expressão do antígeno 503 de Leishmania i. Chagasi expresso em Escherichia coli. A bactéria foi cultivada em três ensaios diferentes, chamados Cinética A, B, C, onde a concentração do indutor IPTG foi variada em 10, 100 e $1500 \mu \mathrm{M}$, respectivamente. Observou-se que na Cinética C $(1500 \mu \mathrm{M})$, obteve-se uma maior concentração de proteínas totais e a partir de uma análise qualitativa (eletroforese) observou-se que na cinética A e C obteve-se a melhor expressão do antígeno 503. Para purificação do antígeno,utilizou-se resina de níquel sefarose, operada em leito fixo. Os resultados qualitativos da purificação mostraram que não foi eficiente.
\end{abstract}

Palavras Chave: IPTG; Leishmaniose; Escherichia coli recombinante; antígeno 503.

Visceral leishmaniasis is an infectious-parasitic disease caused by protozoa of the genus Leishmania, which can be lethal when there is no adequate treatment. The increasing incidence of this disease makes important the search for alternatives of low cost for rapid diagnosis and vaccine. In this context, the main objective of this research was to evaluate the influence of IPTG on 503 antigen expression of Leishmania i. chagasi expressed in Escherichia coli. The bacteria was cultured in three different assays, called Kinetics A, B, C where the concentration of the IPTG inducer was varied at 10,100 and $1500 \mu \mathrm{M}$ respectively. It was observed that in Kinetics C (1500 $\mu \mathrm{M})$, it was obtained a higher concentration of native proteins and from a qualitative analysis (electrophoresis) it was observed that in Kinetics A and C obtained the best expression of 503 antigen. For purification of the antigen, the Nickel Sepharose Resin, operated in fixed bed was used. The qualitative results of the purification showed that it was not efficient.

Keywords: IPTG; Leishmaniasis; recombinant Escherichia coli; 503 antigen. 


\section{Introdução}

Estima-se que existam em todo o mundo 12 milhões de pessoas infectadas com diversas formas de leishmaniose, e cerca de 350 milhões de pessoas expostas ao risco de infecção (Davies et al, 2003).

Com os avanços da engenharia genética e biologia molecular, tenta-se atingir esses objetivos através da produção de antígenos específicos da Leishmania i. chagasi. Por sua ampla utilização e banco de dados na literatura, foi utilizada a Escherichia coli como hospedeira para a recombinação genética e produção do antígeno.

Um parâmetro que tem mostrado efeito significativo na síntese de proteínas recombinantes é a concentração do indutor, uma vez que a expressão de genes ocorrendo em linhagens de E. coli, muitas vezes, necessita de indução, podendo ser realizada por compostos como o isopropil$\beta$-D- tiogalactopiranosídeo -IPTG, que é um forte indutor químico e representa uma das moléculas indutoras mais utilizadas nos variados sistemas de expressão heteróloga (Zanfonato, 2012).

\section{Metodologia}

\section{MICRORGANISMO}

O microrganismo utilizado foi uma cepa de Escherichia coli M15, contendo o plasmídeo pQE-30 capaz de expressar o antígeno 503 com cauda de histidina.

A cepa de Escherichia coli expressando o antígeno 503 é armazenada a $-80^{\circ} \mathrm{C}$ em microtubos com glicerol a $50 \%$ no Laboratório de Imunogenética do Departamento de Bioquímica da Universidade Federal do Rio Grande do Norte.

\section{PREPARO DO INÓCULO}

Para ativação do microrganismo, $200 \mu \mathrm{L}$ da solução de glicerol, onde se encontra a cepa de Escherichia coli armazenada a $-80 \mathrm{oC}$ que contém o antígeno 503, foram transferidos assepticamente para $50 \mathrm{~mL}$ do meio $2 \mathrm{xTY}$. O meio será previamente esterilizado e depois suplementado com $50 \mu \mathrm{L}$ de ampicilina $(0,1 \mathrm{~g} / \mathrm{L})$ e $50 \mu \mathrm{L}$ de canamicina
$(0,025 \mathrm{~g} / \mathrm{L})$ em frascos Erlenmeyer de $250 \mathrm{~mL}$. Esse cultivo inicial será realizado em incubador rotativo a $37^{\circ} \mathrm{C}$ e 200 rpm, por 12 horas e chamado de pré-inóculo.

Para preparo do inóculo, serão adicionados $5,0 \mathrm{~mL}$ do pré-inóculo a 45, $0 \mathrm{~mL}$ do meio de cultivo $2 \mathrm{xTY}$, contidos em Erlenmeyers de $250 \mathrm{~mL}$ e serão incubados a $200 \mathrm{rpm}$ e $37^{\circ} \mathrm{C}$ por 6 horas. Esta suspensão constitui o inóculo dos ensaios realizados em incubador rotativo e biorreator (Vaz, 2011).

\section{CULTIVO EM INCUBADOR ROTATIVO}

Nos ensaios em incubador rotativo, $45,0 \mathrm{~mL}$ do meio de cultivo 2xTY foram adicionados com 5,0 mL do inóculo em Erlenmeyer de $250 \mathrm{~mL}$ e incubados a $200 \mathrm{rpm}$ e $37^{\circ} \mathrm{C}$ por 12 horas. As amostras foram coletadas a cada duas horas para serem analisadas.

\section{ROMPIMENTO CELULAR}

Para o rompimento celular foi utilizado um tampão de lise a base de ureia cuja composição consiste em NaH2PO4 a 100,0 mM, ureia a 8,0 M, Tris-Cl a 10,0 mM e pH 8,0.

Primeiramente, as células foram armazenadas em banho de gelo por 15 minutos; em seguida, ressuspendidas no tampão de lise e homogeneizadas por 15 minutos em vórtex a $25^{\circ} \mathrm{C}$. Para remover os resíduos, foi realizada a centrifugação a $2800 \mathrm{rpm}$ por 30 minutos. A proteína de $27^{\circ}$ Congresso Nacional dos Estudantes de Engenharia Química - Goiânia Goiás interesse presente no sobrenadante foi transferida para microtubos e analisadas posteriormente (Leitão, 2017).

\section{PURIFICAÇÃO EM LEITO FIXO}

A purificação das proteínas foi realizada por cromatografia de afinidade por metal imobilizado (IMAC) (Qiagen, Valencia, CA) utilizando a resina Níquel Sepharose (GE HEALTHCARE) e uma coluna de leito fixo com volume de 25,0 mL. Assim, 0,5 mL da resina equilibrada com o tampão de lavagem foi adicionada aos tubos de ensaio contendo $2 \mathrm{~mL}$ do lisado. Antes de adicionar à coluna, os tubos foram colocados em Shaker a $200 \mathrm{rpm}$ por 30 minutos em temperatura ambiente. Em seguida o conteúdo de cada tubo foi vertido na coluna e a bomba peristáltica acionada. 
Por fim, a resina foi lavada com $4 \mathrm{~mL}$ do tampão de lavagem duas vezes e a proteína de interesse foi eluída quatro vezes com $1 \mathrm{~mL}$ do tampão de eluição e as amostras coletadas (Vaz, 2011).

\section{DETERMINAÇÃO DA CONCENTRAÇÃO DE PROTEÍNAS TOTAIS}

A quantificação das proteínas totais nas amostras foi realizada pelo método de Lowry (Lowry et al., 1951).

Inicialmente foi preparado $50 \mathrm{~mL}$ do reativo $\mathrm{C}$ adicionando na ordem: $50,0 \mathrm{~mL}$ do reativo $\mathrm{A}$ (solução de $\mathrm{NaOH} 0,1 \mathrm{M}$ com Na2CO3), 500,0 $\mu \mathrm{L}$ do reativo B1 (CuSO4 $1,0 \%)$ e $500,0 \mu \mathrm{L}$ do reativo $\mathrm{B} 2(\mathrm{KNaC} 4 \mathrm{H} 4 \mathrm{O} 6 \cdot 4 \mathrm{H} 2 \mathrm{O} 2,0 \%)$.

As amostras foram diluídas 10 vezes $(10,0 \mu \mathrm{L}$ de amostra para 90,0 $\mu \mathrm{L}$ de água deionizada) e em seguida, foi adicionado $1,0 \mathrm{~mL}$ do reativo $\mathrm{C}$ nos tubos contendo as amostras diluídas, os mesmos foram homogeneizados no vórtex, e deixados 10 minutos em repouso. Para finalizar, $100,0 \mu \mathrm{L}$ de Folin 1,0 N foi adicionado nas amostras, que foram homogeneizadas no vórtex novamente e mantidas em ambiente escuro por 20 minutos.

A leitura foi realizada em espectrofotômetro a $650 \mathrm{~nm}$, em cubeta de plástico. Todas as leituras foram realizadas em duplicatas, e para descontar o valor da absorbância dos reagentes, foi feita a leitura do branco contendo $100,0 \mu \mathrm{L}$ de água deionizada com 1,0 mL do reativo $\mathrm{C}$ e 100,0 $\mu \mathrm{L}$ de Folin. A proteína albumina de soro bovino (BSA) foi usada como padrão na concentração de 0,01 a $0,1(\mathrm{mg} / \mathrm{mL})$.

\section{ELETROFORESE EM GEL DE POLIACRILAMIDA}

As amostras que apresentaram melhores resultados foram avaliadas quanto à presença do antígeno 503 por eletroforese em gel de poliacrilamida a $12 \%$ conforme metodologia descrita por Laemmli (1970).

As amostras foram inicialmente dialisadas em membranas com poro de $12,0 \mathrm{kDa}$ contra $4 \mathrm{~L}$ de água deionizada, a $4{ }^{\circ} \mathrm{C}$ por 18 horas. Imediatamente antes de aplicadas no gel, as alíquotas foram ressuspensas em tampão de amostra $(0,06 \mathrm{mM}$ Tris- $\mathrm{HCl}, 10,0 \%$ glicerol, $2,0 \%$ SDS, 5,0 \% 2-mercaptoetanol e $0,4 \%$ azul de bromofenol, $\mathrm{pH}=6,8)$ e desnaturadas por aquecimento a $90{ }^{\circ} \mathrm{C}$ por 5 minutos em banho Maria. Preparou-se um gel de poliacrilamida a $15 \%$ e a separação eletroforética foi realizada utilizando uma cuba vertical MiniVE (GE Healthcare, Suécia) contendo tampão de corrida $(25,0 \mathrm{mM}$ Tris-HCl, 192,0 mM Glicina, 0,1 \% SDS, $\mathrm{pH}=8,3$ ) a uma voltagem de $150 \mathrm{~V}$. Após o término da corrida, o gel obtido foi revelado pela coloração com nitrato de prata.

\section{DETERMINAÇÃO DA CONCENTRAÇÃO DE ANTÍGENO 503}

A concentração do antígeno 503 foi determinada por densitometria das bandas de proteínas separadas por eletroforese em gel de poliacrilamida (Seção 4.2.8) para isso, utilizou-se o software Image $\mathrm{J}$, em que a imagem digitalizada do gel foi processada gerando curvas, cujos picos são proporcionais a largura e a intensidade de coloração das bandas presentes. Quantificando apenas a área sob a curva correspondente à proteína recombinante de interesse obteve-se o valor numérico representativo do antígeno 503 e a partir destes dois valores calculou-se a fração relativa da proteína recombinante.

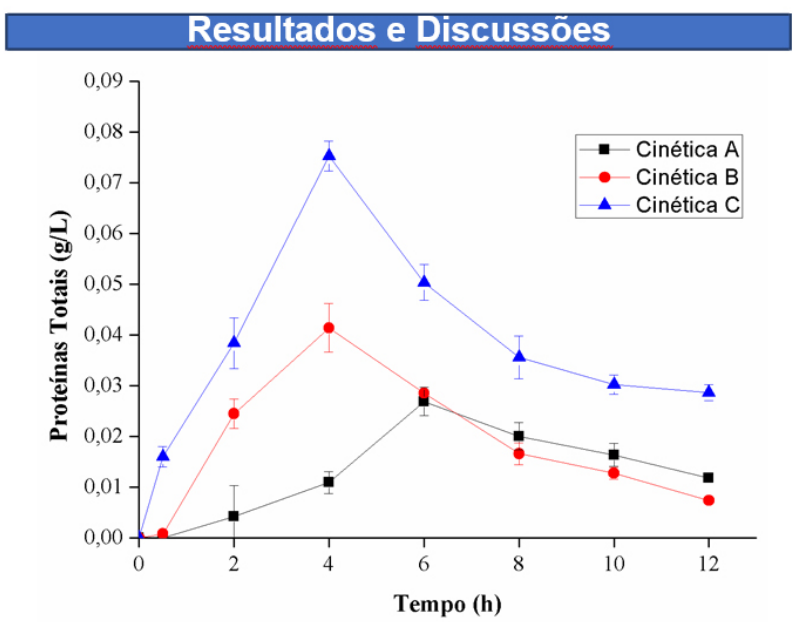

Figura 1. Influência da concentração de IPTG sobre as proteínas totais. 


\section{Artigo Geral 4}

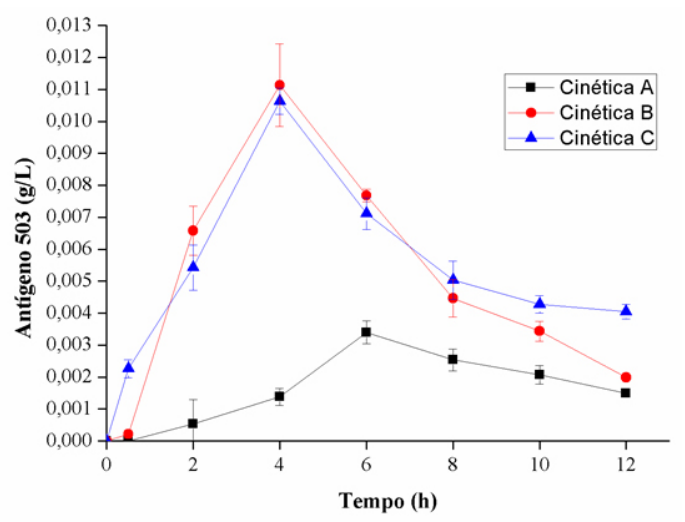

Figura 2. Influência da concentração de IPTG sobre a expressão do Antígeno 503.

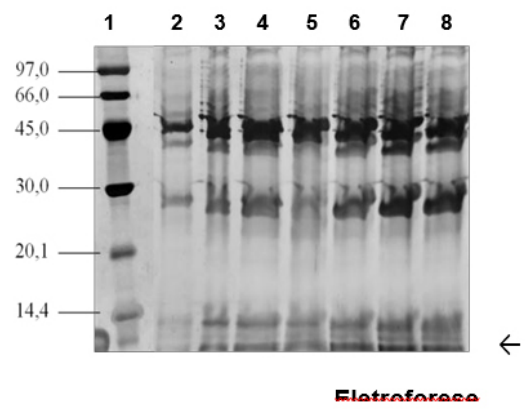

Antígeno 503

1: Marcador de peso molecular;

2: Cinética C em 0,5 horas;

3: Cinética $\mathrm{C}$ em 2 horas;

4: Cinética $\mathrm{C}$ em 4 horas:

5: Cinética $C$ em 6 horas:

6: Cinética $C$ em 8 horas:

7: Cinética C em 10 horas;

8: Cinética C em 12 horas.

Figura 3. Eletroforese para a avaliação da expressão do antígeno 503 na Cinética $\mathrm{C}$.

\section{Conclusões}

Verificou-se que a concentração de $1500 \mu \mathrm{M}$ de IPTG favoreceu a produção de proteínas totais. Em termos de expressão, o ensaio da Cinética B (100 $\mu \mathrm{M}$ de IPTG) e C (1500 $\mu \mathrm{M}$ de IPTG) resultaram em maior produção do antígeno 503 com resultados muito similares de aproximadamente $0,011 \mathrm{~g} / \mathrm{L}$.
A purificação em leito fixo não apresentou bons resultados como pode ser observado pela Figura 3, em nenhuma coluna obteve-se apenas a banda referente ao antígeno 503 .

\section{Referências}

1. Davies, C.R.; Kaye, P.; Croft, S.L.; Sundar, S. Leishmaniasis: new approaches to disease control. British Medical Journal, v. 326, p. 377-382. 2003.

2. Laemmli, U. K. Cleavage of structural proteins during the assembly of the head of bacteriophage T4. Nature, v. 227, p. 680-685, 1970.

3. Leitão, A. L. O. S. Avaliação de métodos de rompimento celular e de diferentes metais imobilizados em resina Streamline Chelating para purificação do antígeno 503 de Leishmania i. chagasi. Dissertação (Mestrado em Engenharia Química), Universidade Federal do Rio Grande do Norte, 2017.

4. Lowry, O. H.; ROSEBROUG, N. J.; FARR, A. L.; et al. Protein measurement with the Folin phenol reagent. J. Biol Chem, v. 193, p. 265-275, 1951.

5. Vaz, M. R. F. Influência das condições de cultivo na produção de antígenos recombinantes de Leishmania i. chagasi utilizando Escherichia coli M15 cultivada em incubador rotativo e biorreator. Tese (Doutorado em Engenharia Química), Universidade Federal do Rio Grande do Norte, 2011.

6. Zanfonato, K. Produção de poli (3-hidroxibutirato) por linhagens de Escherichia coli dh5 $\alpha$ e jm101 recombinantes. Tese (Doutorado), Universidade Federal de Santa Catarina, Departamento de Engenharia Química e Engenharia de Alimentos. 96p,2012.

\section{Estéfani A. Asevedo, Vitor T. I. Ribeiro \& Everaldo S. dos Santos}

Universidade Federal do Rio Grande do Norte,Natal/RN, asevedoestefani@, gmail.com, (IC);

*E-mail: everaldo@eq.ufrn.br 